\title{
REDUKCJA WYMIAROWOŚCI DANYCH A SELEKCJA CECH W ZASTOSOWANIU DO PROGNOZOWANIA MAKSYMALNEGO DOBOWEGO OBCIĄŻENIA ELEKTROENERGETYCZNEGO
}

\author{
Siwek Krzysztof \\ Politechnika Warszawska, Instytut Elektrotechniki Teoretycznej i Systemów Informacyjno-Pomiarowych
}

Streszczenie. Prognozowanie obciążen w systemie elektroenergetycznym jest ważnym problemem praktycznym zarówno z technicznego jak i ekonomicznego punktu widzenia. W matych systemach problem ten jest stosunkowo trudny do rozwiazania ze względu na duża zmienność przebiegu obciązenia. Do jego rozwiązania niezbędne jest zastosowanie dobrego predykatora i wyselekcjonowanie cech procesu wpływajacych na prognozę. Artykut przedstawia dwie metody selekcji cech - algorytm genetyczny oraz algorytmy redukcji wymiarowości. Jako predykator użyta była maszyna wektorów podtrzymujacych działajaca w trybie regresji (SVR). Zaprezentowano i omówiono uzyskane wyniki na rzeczywistych danych pomiarowych.

Słowa kluczowe: prognozowanie obciążeń elektroenergetycznych, redukcja wymiarowości, algorytm genetyczny, maszyna wektorów podtrzymujących

\section{DATA REDUCTION VERSUS FEATURE SELECTION IN APPLICATION OF DAILY MAXIMUM POWER LOAD FORECASTING}

\begin{abstract}
Load forecasting task of small energetic region is a difficult problem due to high variability of power consumption. The accurate forecast of the power in the next hours is very important from the economic point of view. The most important problems in prediction are the choice of predictor and selection of features. Two methods of features selection was presented - simple selection using of genetic algorithm and dimensionality reduction methods for creating new features from many available measured data. As a predictor the Support Vector Machine working in regression mode (SVR) was chosen. The load forecasting results with SVR are presented and discussed.
\end{abstract}

Keywords: load power forecasting, dimensionality reduction, genetic algorithm, support vector machine

\section{Wstęp}

Krótkoterminowe prognozowanie obciążeń w małym rejonie energetycznym jest bardzo trudnym problemem praktycznym ze względu na dużą zmienność konsumpcji energii elektrycznej w stosunku do wartości średniej. Dokładność prognozy przekłada się bezpośrednio na zyski lub ich brak, uzyskane przez dostawców energii $\mathrm{z}$ jednej strony oraz koszty ponoszone przez odbiorców $\mathrm{z}$ drugiej strony. W interesie obu stron leży więc wykonanie jak najdokładniejszych prognoz zużycia energii elektrycznej w różnych horyzontach czasowych, w tym prognoz krótkoterminowych na następne 24 godziny. Z punktu widzenia bezpieczeństwa systemu, jak również mającym uzasadnienie ekonomiczne, jest predykcja obciążenia maksymalnego w następnym dniu. Artykuł przedstawia badania dotyczące tego zagadnienia.

\section{Opis problemu}

Najważniejszym problemem jaki należy rozwiązać przy wykonywaniu prognozy jest wybór narzędzia do prognozowania i określenie cech procesu wpływających w największym stopniu na prognozę.

W przypadku dużej bazy danych pomiarowych rejestrujących w dłuższym czasie otrzymuje się ogromny zestaw potencjalnych cech opisujących prognozę. Powstaje problem wyboru stosunkowo małej liczby cech najlepiej reprezentujących badany proces. Artykuł prezentuje dwa podejścia do rozwiązania tego problemu: zastosowanie algorytmów genetycznych do selekcji historycznych wartości pomiarowych oraz redukcja wymiarowości i przetworzenie długiego wektora danych pomiarowych na krótki wektor cech.

$\mathrm{Na}$ bazie poprzednich prac jako narzędzie do predykcji wybrano maszynę wektorów podtrzymujących pracującą w trybie regresji (Support Vector Machine in regression mode, SVR) $[6,7,9]$.

\section{Algorytmy genetyczne}

Algorytmy genetyczne (AG) są to algorytmy optymalizacji globalnej wzorowane na mechanizmach doboru naturalnego. $\mathrm{W}$ procesie ewolucji wybrane osobniki przekazują swojemu potomstwu własne cechy i jednocześnie, w procesie krzyżowania cechy najlepiej przystosowanych osobników mieszają się, dając kombinacje dotąd nie występujące w populacji. Dodatkowy czynnik losowy wynikający z mutacji jeszcze bardziej różnicuje osobniki potomne.
W kolejnych pokoleniach tworzone sa nowe osobniki posiadające taki zestaw cech, który zapewnia coraz lepsze przystosowanie do warunków panujących w środowisku czyli do rozwiązywania zadanego problemu.

Algorytmy genetyczne uznawane są za dobrą metodę optymalizacyjna pozwalajaca znaleźć minimum globalne w przypadku bardzo dużej przestrzeni danych. Algorytmy genetyczne sa $\mathrm{z}$ powodzeniem stosowane $\mathrm{W}$ rozwiazywaniu zagadnień naukowych, inżynierskich jak i finansowych $[1,4]$.

\subsection{Kodowanie informacji w chromosomach}

Algorytmy genetyczne bazują na przetwarzaniu zakodowanego w postaci chromosomów i genów zadania optymalizacyjnego. Chromosomy i geny definiuja osobniki, dla których oblicza się tzw. funkcję przystosowania, która w procesie ewolucji powinna przybierać coraz wyższe wartości.

Dla klasycznych genów binarnych poszczególne pola chromosomów przyjmują wartości zero lub jeden. Kodowanie takie można zastosować w selekcji cech. Wektor chromosomów reprezentować może kolejne cechy, wartość jeden oznaczać będzie wybór danej cechy, wartość zero - usunięcie tej cechy.

\subsection{Operatory genetyczne}

Do podstawowych operatorów genetycznych wykorzystanych w pracy zalicza się selekcję, krzyżowanie i mutację.

Selekcja jest operatorem wybierania osobników najlepiej przystosowanych do środowiska, osobniki te przekazują swój materiał genetyczny potomstwu. Najczęściej stosowaną metodą selekcji jest metoda tzw. koła ruletki.

Operator krzyżowania polega na wymianie fragmentów chromosomów pomiędzy osobnikami z rodzicielskimi. W efekcie powstają nowe osobniki potomne $\mathrm{z}$ innymi wektorami cech.

Operacja mutacji pełni ważną rolę $w$ algorytmach genetycznych. Polega na stosunkowo rzadkiej i przypadkowej zmianie wartości genów na przeciwne. Działanie takie pozwala na powstawanie niespotykanych we wcześniejszych populacjach zestawów cech.

\subsection{Algorytm genetyczny do selekcji cech}

Po wyborze populacji początkowej (najczęściej w sposób losowy) następuje iteracyjny proces wymiany kolejnych pokoleń. W każdym pokoleniu dokonuje się selekcji osobników, ich krzyżowania i ewentualnej mutacji. Kolejne pokolenia stają się coraz lepiej przystosowane do rozwiązania problemu 
optymalizacyjnego, a po osiągnięciu zadanego stopnia przystosowania populacji (lub spełnienia innych warunków stopu jak maksymalna liczba iteracji) algorytm zostaje zatrzymany a najlepiej przystosowany osobnik z ostatniej populacji uznawany jest za końcowe rozwiązanie [4].

W każdej iteracji dla każdego osobnika uczona i testowana jest sieć neuronowa wykonująca predykcję. Binarne chromosomy poszczególnych osobników definiują postać wektora wejściowego dla sieci neuronowej.

Rysunek 1 przedstawia schemat procedury wyboru cech i predykcji przy użyciu algorytmu genetycznego oraz maszyny SVR.

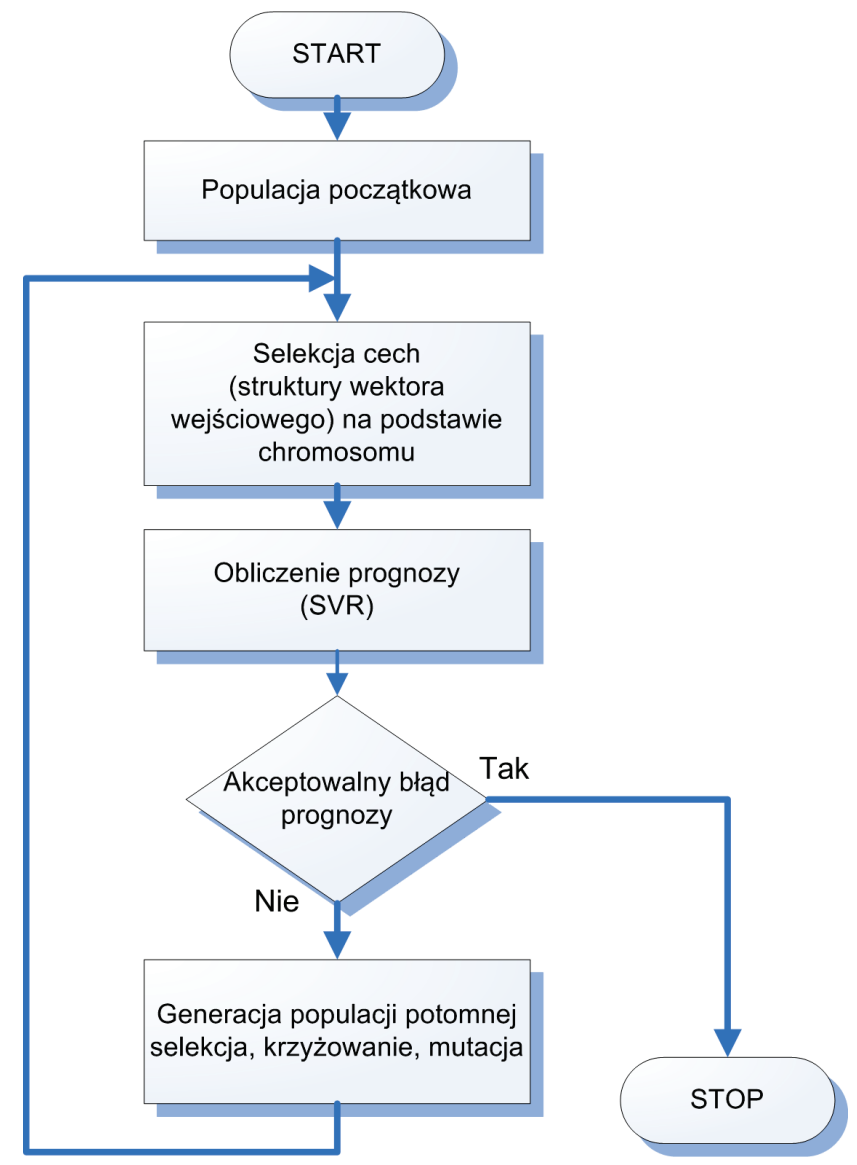

Rys.1. Schemat algorytmu genetycznego do selekcji cech

\section{Metody redukcji wymiarowości}

Redukcja wymiarowości wektora jest to zadanie liniowego bądź nieliniowego rzutowania zbioru wektorów $\mathbf{x}=\left[x_{1}, x_{2}, \ldots x_{p}\right]^{T}$ na zbiór wektorów $\mathbf{s}=\left[s_{1}, s_{2}, \ldots s_{k}\right]^{T}$ o mniejszej wymiarowości, gdzie $k<p$. Rzutowanie takie powinno zachowywać wybrane cechy zbioru wektorów wejściowych, w tym odległości w sensie wybranej metryki pomiędzy wektorami po transformacji $[2,13]$.

\subsection{Liniowa transformacja PCA}

Transformacja PCA polega na przekształceniu układu współrzędnych maksymalizującego wariancje kolejnych czynników głównych. Redukcja wymiarowości możliwa jest przy pominięciu czynników najmniej znaczących [5].

Najczęściej spotykana metoda obliczenia macierzy rzutującej polega na obliczeniu macierzy korelacji danych macierzy $\mathbf{X}$ powstałej z wektorów $\mathbf{x}$ - wzór (1)

$$
\mathbf{R}_{x x}=\frac{1}{n} \mathbf{X} \mathbf{X}^{T}
$$

a nastepnie dokonaniu rozkładu na wektory własne $\mathbf{R}_{x x}=\mathbf{U S U}^{T}$. Końcowa macierz rzutująca $\mathbf{W}^{k \times p}$ powstaje po pozostawieniu początkowych $k$ wektorów macierzy $\mathbf{U}^{T}$, odpowiadających największym wartościom własnych i usunięciu pozostałych.

Transformacja PCA realizowana jest jako operacja liniowa wzór (2)

$$
\mathbf{s}=\mathbf{W} \cdot \mathbf{x}
$$

\subsection{Rzutowanie Sammona}

Rzutowanie Sammona należy do grupy metod nieliniowych. Metoda ta zaproponowana $\mathrm{w}$ [8] to nieliniowa metoda polegająca na minimalizacji funkcji błędu $E$ odległości pomiędzy elementami wektora $\mathbf{x}$ w przestrzeni oryginalnej i ze zredukowaną wymiarowością (3).

$$
E=\frac{1}{\sum_{i<j} d_{i j}^{*}} \sum_{i<j} \frac{\left(d_{i j}^{*}-d_{i j}\right)^{2}}{d_{i j}^{*}}
$$

Symbol $d_{i j}^{*}$ opisuje odległość $\mathrm{w}$ oryginalnej przestrzeni, a $d_{i j}$ w przestrzeni zredukowanej.

Metoda Sammona jest iteracyjna, oparta na uproszczonej metodzie optymalizacji Newtona, zwykle największego spadku, z punktem startowym losowym lub obliczonym na podstawie wektorów własnych [2].

\subsection{Przeksztalcenie t-SNE}

Przekształcenie Stochastic Neighbor Embedding (SNE) należy również do grupy przekształceń nieliniowych. Polega na konwersji odległości euklidesowej pomiędzy punktami w przestrzeni oryginalnej na prawdopodobieństwo warunkowe, odzwierciedlające podobieństwo między tymi punktami w przestrzeni zredukowanej $[12,13]$.

Podobieństwo punktu $\mathbf{x}_{j}$ do $\mathbf{x}_{i}$ w przestrzeni oryginalnej jest prawdopodobieństwem warunkowym $p_{j \mid i}$ takim, że punkt $\mathbf{x}_{j}$ będzie najbliższym sąsiadem $\mathbf{x}_{i}$ przy założeniu, że sąsiedztwo jest wybierane proporcjonalnie do wartości gęstości prawdopodobieństwa Gaussa przy centrum leżącym w $\mathbf{x}_{j}$.

$$
p_{j \mid i}=\frac{\exp \left(-\left\|\mathbf{x}_{i}-\mathbf{x}_{j}\right\|^{2} / 2 \sigma_{i}^{2}\right)}{\sum_{k \neq i} \exp \left(-\left\|\mathbf{x}_{i}-\mathbf{x}_{k}\right\|^{2} / 2 \sigma_{i}^{2}\right)}
$$

Dla wektorów leżących blisko siebie prawdopodobieństwo to jest wysokie, natomiast dla punktów odległych od siebie niskie i dążące do zera dla zbioru wektorów odseparowanych od siebie.

$\mathrm{W}$ przypadku dobrego mapowania wektory $\mathbf{s}_{i}, \mathbf{s}_{j}$ w przestrzeni o zredukowanym wymiarze, $\mathrm{z}$ prawdopodobieństwem warunkowym $q_{j i l}$, powinny dobrze odzwierciedlać podobieństwo odpowiednich wektorów $\mathbf{x}_{i}, \mathbf{x}_{j}$ z przestrzeni oryginalnej. Dla takiej sytuacji prawdopodobieństwa warunkowe $p_{j \mid i}$ oraz $q_{j \mid i}$ powinny być sobie równe.

Zadaniem rzutowania SNE jest znalezienie takiego przekształcenia, które minimalizuje rozbieżność między prawdopodobieństwem warunkowym $\mathrm{w}$ przestrzeni zrzutowanej $p_{j \mid i}$ oraz $\mathrm{w}$ przestrzeni oryginalnej $q_{j \mid i}$. Przekształcenie SNE minimalizuje sumę dywergencji Kullbacka-Leiblera zdefiniowanych po wszystkich kombinacjach punktów podlegających rzutowaniu. Do minimalizacji również używana jest metoda największego spadku.

Odmiana tego przekształcenia nazywana t-SNE jest modyfikacją klasycznego SNE, wprowadzająca poprawki umożliwiające poprawne rzutowanie przy obecności dużej liczby danych odstających [12]. 


\subsection{Metoda losowa}

W metodzie losowej (random projection) elementy macierzy rzutującej $\mathbf{W}$ wybiera się w sposób losowy według zależności (5) $\mathrm{z}$ prawdopodobieństwem $p$

$$
w_{i j}=\left\{\begin{array}{l}
-1 / \sqrt{3}, p=1 / 6 \\
1 / \sqrt{3}, p=1 / 6 \\
0, p=2 / 3
\end{array}\right.
$$

Dowiedziono [2], że taki wybór macierzy pozwala na prawidłowe zachowanie najważniejszych cech zbioru danych po rzutowaniu na mniejszą liczbę wymiarów.

Metoda ta jest szczególnie polecana dla dużych zbiorów danych, gdzie koszt obliczeniowy $\mathrm{w}$ innych metodach $\mathrm{np}$. PCA nie pozwala na obliczenie macierzy rzutującej w akceptowalnym czasie.

\section{Prognoza zapotrzebowania na energię}

Badaniom podlegało zadanie prognozowania obciążenia maksymalnego $\mathrm{w}$ następnym dniu dla małego rejonu energetycznego $\mathrm{z}$ dominującym obciążeniem o charakterze komunalnym (mieszkania, małe zakłady pracy, biura).

Dostępna baza obejmowała dane obciążenia systemu oraz parametry meteorologiczne za lata 2002-2010. Rejon ten charakteryzował się zużyciem energii elektrycznej z wartością średnią wynoszącą ok. $350 \mathrm{MW} \mathrm{w}$ dostępnym okresie pomiarów. Rysunek 2 przedstawia znormalizowane obciążenie maksymalne w dniach w latach 2002-2010.

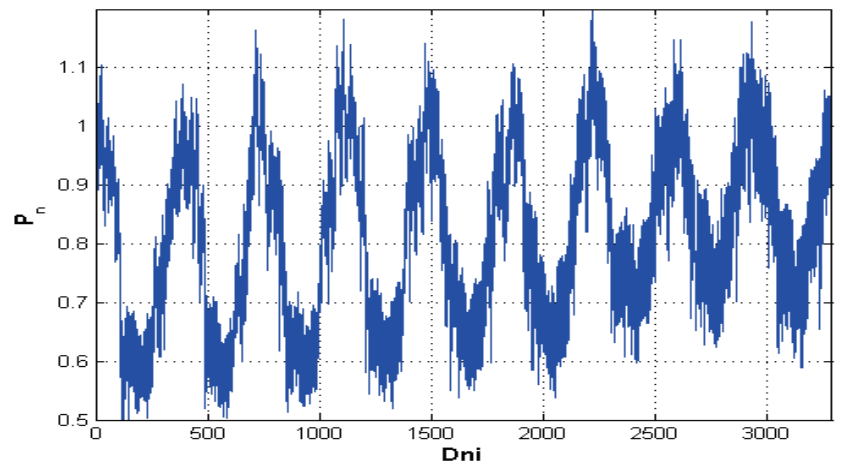

Rys. 2. Znormalizowanie maksymalne obciażenie wybranego rejonu energetycznego w latach 2002-2010

\subsection{Cechy wpływające na prognozę}

Dokładność prognozowania zużycia energii elektrycznej zależy od charakteru obciążenia i wielkości w danym rejonie energetycznym, jak również od parametrów meteorologicznych takich jak temperatura, prędkość wiatru, wilgotność, nasłonecznienie.

$\mathrm{Na}$ prognozę wpływają ponadto wskaźniki kalendarzowe, na przykład typ dnia (roboczy, świąteczny), pora roku, szczyty obciążeń.

$\mathrm{W}$ systemie elektroenergetycznym z zasady nie występują gwałtowne zmiany obciążenia $\mathrm{z}$ godziny na godzinę i jednocześnie istnieje duża powtarzalność obciążenia w kolejnych dniach tego samego typu. Wynika $\mathrm{z}$ tego, że do wektora cech należy zaliczyć wybrane wartości obciążenia $\mathrm{z}$ przeszłości, ich kombinacje oraz trendy ich zmian.

$\mathrm{Na}$ konsumpcję energii elektrycznej duży wpływ mają również czynniki pogodowe. Bez względu na charakter obciążenia najczęściej korelacja ta jest bardzo wysoka. Przy niskiej temperaturze zewnętrznej zużycie energii rośnie głównie na potrzeby ogrzewania, czy to w budynkach mieszkalnych czy przemysłowych. W dużym stopniu na ogrzewanie ma również wpływ siła wiatru i częściowo jego kierunek. W ostatnich latach obserwuje się ponadto wzrost obciążenia systemu w gorących miesiącach na potrzeby klimatyzacji, tak więc czynniki pogodowe mają znaczenie zarówno w okresach letnich i zimowych.

Wpływ nasłonecznienia na zużycie energii elektrycznej przekłada się bezpośrednio poprzez konieczność włączania oświetlenia i ewentualnie dodatkowego ogrzewania w pochmurne dni.

W prognozowaniu obciążeń należy brać pod uwagę wszystkie wymienione cechy, jak również ich zmiany (trendy). Ogólny wzór na obliczenie prognozy maksymalnej na następny dzień można przedstawić następująco

$$
\begin{aligned}
& P_{\max }(d+1)=f(t d, s, P(d-1), P(d-2), \ldots, \\
& P(d-D), t(d+1), \\
& \quad t(d), t(d-1), \ldots, \\
& t(d-D), w s(d+1), w s(d), w s(d-1), \ldots, \\
& \quad w s(d-D), h(d+1), h(d), h(d-1), \ldots, \\
& h(d-D), i s(d+1), \\
& \quad i s(d), i s(d-1), \ldots, \\
& i s(d-D), \operatorname{tr}(P), \operatorname{tr}(t), \operatorname{tr}(w s), \operatorname{tr}(h), \operatorname{tr}(i s))
\end{aligned}
$$

w którym $f$ jest szukaną funkcją nieliniową opisującą prognozę, $d$ jest numerem kolejnego dnia w okresie prognozy, $P_{\max }(d+1)$ oznacza prognozę wartości maksymalnej na dzień następny, $t d$ - typ dnia i $s$ - porę roku dla dnia następnego, $t$ - temperaturę, $w s$ - prędkość wiatru, $h$ - wilgotność oraz is - nasłonecznienie. Symbole $\operatorname{tr}(P), \operatorname{tr}(t), \operatorname{tr}(w s), \operatorname{tr}(h), \operatorname{tr}(i s)$ oznaczają trendy (współczynniki kierunkowe funkcji liniowych) zmian wymienionych wielkości w wybranych przedziałach czasowych. Wielkości oznaczone jako $(d+1)$ są prognozą (również pogody), a pozostałe sa wartościami historycznymi z $D$ dni wstecz.

W przypadku rejestrowania danych w odstępach godzinnych powyższy wzór należy rozbudować o wielkości dla kolejnych 24 godzin dnia. Powoduje to znaczne zwiększenie wymiaru wektora wejściowego dla predykatora (np. sieci neuronowej), co może skutkować słabą generalizacją. Pożądane jest więc skrócenie tego wektora w taki sposób, aby zawierał jedynie informacje najbardziej istotne dla opisu procesu prognozowania.

\section{Wyniki badań eksperymentalnych}

Dane pomiarowe $\mathrm{z}$ lat 2002-2010 zostały podzielone losowo na zbiór uczący i testujący w stosunku $65 \%$ - 35\%. Zgodnie ze wzorem (6) utworzono wektor 117 cech wpływających na prognozę. Do obliczenia funkcji nieliniowej $f$ użyto maszyny wektorów podtrzymujących (SVR) z radialną funkcją jądra $[10,11]$

W przypadku uwzględnienia całego wektora 117 cech uzyskano błąd prognozy MAPE na wybranych danych testujących wynoszący $15,9 \%$. Tak wysoki błąd MAPE świadczy o słabej generalizacji, sieć nie zdołała wychwycić charakteru procesu z prezentowanych jej danych uczących i prawidłowo obliczyć prognozę na dzień następny.

W kolejnych krokach przeprowadzono selekcję najlepszych cech wejściowych przy użyciu algorytmu genetycznego oraz zmniejszenie wymiarowości wektora wejściowego metodami redukcji wymiarowości PCA, Sammona, t-SNE oraz metodą losową.

W przypadku użycia algorytmu genetycznego na wejściu sieci pozostają wyselekcjonowane rzeczywiste wartości pomiarowe wielkości fizycznych - obciążenie, temperatura, siła wiatru, nasłonecznienie $\mathrm{i}$ wybrane trendy tych wielkości $\mathrm{z}$ poprzednich dni i godzin. Uznano, że ze względu na znaczne różnice pomiędzy charakterystykami obciążenia dla różnych pór roku i różnych typów dni (roboczy, świąteczny) cechy takie jak typ dnia i pora roku zawsze będą należały do wektora wejściowego. Tabela 1 przedstawia uzyskane wyniki predykcji obciążenia maksymalnego w następnym dniu. 
Tabela 1. Wyniki predykcji (bład MAPE) na danych testujacych po zastosowaniu selekcji cech algorytmem genetycznym

\begin{tabular}{|c|c|}
\hline Wymiar wektora & Błąd MAPE [\%] \\
\hline 12 & 9.1201 \\
\hline
\end{tabular}

Algorytm genetyczny wyselekcjonował 10 cech wpływających w największym stopniu na predykcję. Do wektora wejściowego dla sieci SVR dołączono 2 omówione wcześniej cechy opisujące typ dnia i porę roku.

$\mathrm{Z}$ metod redukcji wymiarowości (tabela 2) najlepsza okazała się metoda t-SNE, błąd predykcji nie zależał $\mathrm{w}$ dużym stopniu od długości wektora w zakresie od 6 do 26. Porównywalne wynik uzyskano dla metody redukcji Sammona, jednakże jedynie dla długiego wektora wejściowego o wymiarze 26. Metoda PCA pozwalała na uzyskanie małego błędu dla najkrótszego wektora wejściowego. Oznacza to, że metoda PCA pozwala na zawarcie największej liczby informacji w najmniejszym wektorze. Przy długim wektorze wejściowym jej efektywność znacznie spadała.

Koszt obliczeniowy największy jest dla metod Sammona oraz t-SNE, ponieważ wiąże się to $\mathrm{z}$ koniecznością przeprowadzenia optymalizacji metodami gradientowymi podczas redukcji.

Metoda losowa (RP) daje nieco większy błąd predykcji przy niewielkiej wymiarowości danych. Wielką zaletą tej metody jest prostota i szybkość działania oraz małe wymagania co do pamięci.

Tabela 2 przedstawia wyniki predykcji wartości maksymalnej w następnym dniu po zredukowaniu wymiarowości wektora wejściowego z początkowych 117 różnymi metodami.

Tabela 2. Wyniki predykcji (bład MAPE) na danych testujacych po redukcj wymiarowości wybranymi metodami

\begin{tabular}{|c|c|c|c|c|}
\hline $\begin{array}{c}\text { Wymiar } \\
\text { wektora }\end{array}$ & PCA & Sammon & t-SNE & RP \\
\hline 6 & $\mathbf{9 . 4 1 2 7}$ & 10.1198 & $\mathbf{9 . 3 9 7 6}$ & $\mathbf{1 1 . 2 4 4 3}$ \\
\hline 14 & 11.2221 & 10.9132 & 9.5541 & 12.0091 \\
\hline 26 & 12.8104 & $\mathbf{9 . 4 9 7 1}$ & 9.7605 & 12.3077 \\
\hline
\end{tabular}

\section{Wnioski końcowe}

We wszystkich przypadkach uzyskano znaczącą poprawę jakości predykcji z początkowego błędu MAPE wynoszącego $15.9 \%$ dla pełnego wektora wejściowego składającego się ze 117 cech.

Obie zaprezentowane metody wyboru cech działają na innej zasadzie. Algorytm genetyczny dokonuje selekcji poszczególnych składowych wektora wejściowego, natomiast algorytmy redukcji tworzą zupełnie nowe cechy na podstawie podanego zestawu danych.
Metody redukcji mogą mieszać ze sobą informacje ważne dla predykcji z informacjami nieważnymi, a wręcz szkodliwymi i wprowadzającymi błędy. Stąd obserwuje się lepszą predykcję w przypadku selekcji cech niż przy zastosowaniu metod redukcji wymiarowości.

W przypadku metody PCA najwięcej informacji skojarzonych jest $\mathrm{Z}$ sześcioma najważniejszymi wartościami własnymi. Z przeprowadzonych badań wynika, że użycie tylko tych informacji pozwala na efektywne obliczenie predykcji. Ponadto zaletą jest zwarta struktura sieci neuronowej, która zapewnia dobrą generalizację.

W przypadku selekcji cech algorytmem genetycznym następuje proces wyboru nie tylko tych elementów wektora, które odpowiadają za dobrą prognozę, ale również zestawu takich cech.

Oba opisane w pracy podejścia do skrócenia wymiarowości wektora wejściowego dały dobre wyniki. Rezultaty prognozy wykonanej przy użyciu sieci SVR dla zredukowanych wektorów wejściowych są znacznie lepsze niż dla pełnego wektora $117 \mathrm{cech}$.

\section{Literatura}

[1] Ashlock D.: Evolutionary Computation for Modeling and Optimization. Berlin, Germany: Springer-Verlag, 2006

[2] Fodor I.: A Survey of Dimension Reduction Techniques. Raport techniczny, 2002.

[3] Gill P., Murray W., Wright M.: Practical optimization. Academic Press, London 1981.

[4] Goldberg D.: Genetic Algorithms in Search, Optimization, and Machine Learning. Reading, MA: Addison-Wesley, 1989.

[5] Jackson J.E.: User guide to principal components. Wiley, NY, 1991

[6] Osowski S., Siwek K., Świderski B., Mycka Ł.: Prediction of power consumption for small power region using indexing approach and neural network. Lecture Notes on Computer Science, LNCS-6352, 2010, str. 54-59.

[7] Osowski S., Siwek K.: Regularization of neural networks for load forecasting in power system. IEE Proc. GTD, 149, 2002, 340-345.

[8] Sammon J.W.: A nonlinear mapping for data structure analysis. IEEE Transactions on Computers, No. 18, 1969, str. 401-409.

[9] Siwek K., Osowski S., Świderski B.: Trend elimination of time series of 24-hour load demand in the power system and its application in power forecasting. Przegląd Elektrotechniczny, vol. 87, No 3, 2011, str. 249-253.

[10] Schölkopf B., Smola A.: Learning with kernels. MIT Press, Cambridge MA, 2002.

[11] Vapnik V.: Statistical learning theory. Wiley, NY, 1998.

[12] Van der Maaten L., Hinton G.: Visualizing Data using t-SNE, Journal of Machine Learning Research, Vol. 9, 2008, str. 2579-2605.

[13] Van der Maaten L., Postma, E.: Dimensionality reduction: a comparative review. 2009, int. report TiCC TR 2009-005.

Dr hab. inż. Krzysztof Siwek

e-mail: ksiwek@iem.pw.edu.p

Adiunkt w Instytucie Elektrotechniki Teoretycznej i Systemów Informacyjno-Pomiarowych na Wydziale Elektrycznym Politechniki Warszawskiej.

W obszarze jego zainteresowań leżą metody sztucznej inteligencji $\mathrm{W}$ zastosowaniach praktycznych szczególnie w rozwiązywaniu problemów predykcji i klasyfikacji.

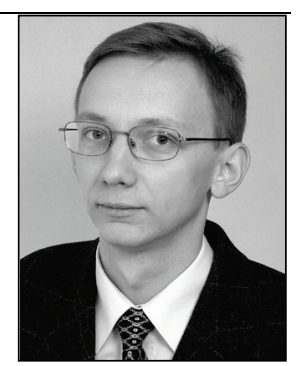

Artykuł recenzowany

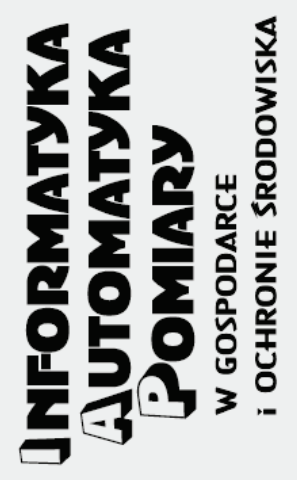

\section{Zapraszamy na naszą stronę internetową: WWW . IAPGOS . PL} gdzie znajdziecie Państwo:

- informacje nt. zamieszczania reklam,

- wykaz prac opublikowanych w latach 2011 i 2012,

- procedurę recenzowania,

- wykaz recenzentów prac opublikowanych w poprzednich latach,

- aktualną formatkę artykułu oraz druk recenzji,

- dostęp on-line do artykułów (już wkrótce). 